\title{
Chua, Amy. (2011). Battle Hymn of the Tiger Mother. New York: Penguin Books.
}

\author{
Reviewed by: Raina Shaw, MacEwan University
}

"Battle Hymn of the Tiger Mother" by Amy Chua juxtaposes Chinese-style "tiger" parenting and Western-style parenting with personal anecdotes. Throughout her memoir, Chua chronicles her experiences as the titular "tiger mother" raising her two daughters in America. She contrasts her Chinese methods with "Western" parenting methods. However, she starts to experience the unique challenges of raising children in the "Chinese" manner. At the same time, her daughters still absorb "Western" ideas from the external world, which often contradicts Chua's parenting philosophy. Chua comes to realize that tiger-style parenting in the United States is a particularly unique challenge due to the conflicting cultures inside and outside the home, which both socialize her children. The memoir illustrates the differences between Chinese and Western parenting and how child-rearing is both the parents' responsibility and the agents of socialization outside the home. A notable point of contention between Chinese-style and Western-style parenting is accommodation, whether a child should accommodate authority or if authority should accommodate the child. This conflict encompasses more abstract cultural differences regarding individualism, rebellion, and children's self-esteem.

Chua clarifies that a "Chinese" or "tiger" parent does not necessarily need to be from China. The terms "Chinese" and "Western" parents refer to parenting styles. The most notable difference between the two is ideas of accommodation and who should accommodate if the child 
struggles. A Chinese parent expects a child to accommodate the external world. This includes obedience to their parents, authority figures and adhering to external societal standards and expectations. For example, a Chinese mother believes that "if your child ever disagrees with a teacher or coach, you must always take the side of the teacher or coach" (p. 5). Chua notes that Chinese mothers attribute failure to the responsibility of a child who did not try hard enough (p. 52). By contrast, the "Western" parent refers to a more permissive parent, often associated with white North Americans. They would prioritize the child's individual wants and desires and expect the external world to accommodate them. Chua assumes that if a child struggles in school, the Western parent would "challenge the way the subject is taught or call into question the teachers' credentials" (p. 52). The Western parent guards a child from the possibility of "failing," so they alter the environment in which the child had failed. They believe the authority or environment surrounding that child, such as teachers, the school system, or society, are to blame for their child's lack of success. The Chinese parent assumes that the child is at fault, and therefore must accommodate external authority and established standards. The Western parent believes the authorities and established standards must accommodate the individual child.

This conflict regarding accommodation connects to Chinese and Western cultural differences regarding individualism and rebellion in children. Chua observes that Western media aimed at children typically root for characters who defy their parents and authority figures; it is "the parents who need to be taught a life lesson by their children" (p. 24). By contrast, the Chinese prize complete obedience and dedication to one's parents. Unlike a Western child, Chua recalls being afraid of parental disapproval and that "it just wouldn't occur to children to question, disobey, or talk back to their parents" (p. 24). The Western praise of rebellion significantly affected Chua's 
second-born daughter, Lulu. She notes how Lulu displayed traits of rebellion that are prized in American society but looked down upon in Chinese society, even as a young child (p. 38). Frustrated, Chua attributes Lulu's rebellion to American cultural influence. For example, as Lulu was uncooperative during a family trip to Moscow and refused to try certain dishes, Chua scolded her by saying that there is nothing "more common and low than an American teenager who won't try things" (p. 205). Compared to Chinese culture, Western culture depicts rebellion and backtalk as a formative stage in a child's development, so Western parents raise their children in a way that presents such behavior as a default, such as exposing them to examples of it through media. Chinese parents, by contrast, do not expose their children to normalized rebellion, so they raise their children in a manner that presents obedience as a default to follow.

The contrasting attitudes on accommodation also translate to contrasting perspectives on children's self-esteem. A Chinese parent does not hesitate to criticize or shame a child when they fail. According to Chua, the Chinese parent "assumes strength" of the child to withstand scathing criticism, which helps them improve (p. 52). This attitude of Western prioritization of self-esteem over objective achievement is also present in media aimed at children. Chua notes how Disney movies favour heroines who start as obedient daughters and acquire a sense of "freedom" as the story progresses, learning to let go of values such as achievement and gaining approval of authority and establishment (p. 193). Chua opposes this type of message, as she believes this is "Disney's way of appealing to people who never win any prizes" (p. 193). The character arc illustrates a character forgoing achievement under established standards. In other words, this arc represents a character letting go of "Chinese" values in favour of "Western" ones. Chua understands this as catering to the self-esteem of the children who watch these movies. Even if the child never wins 
any prizes, the child can still identify with the heroine who rejects the notion of objective achievement (p. 193). Western parents prioritize salvaging the child's self-esteem. They do this by praising the child and shielding them from the evidence that they may be at fault for failure. Chinese parents, conversely, prioritize objective achievement by a set standard, not self-esteem. In other words, Western-parenting is more child-centric, whereas Chinese-parenting is more parent-centric.

The conflicts regarding accommodation, self-esteem, and individualism reveal the types of traits Western and Chinese parents wish to instill in their children. These traits in question are informed by what the respective cultures demand out of people. Western countries are culturally individualist, prizing rebellion and a strong sense of personal identity, so Western parents raise their children in a manner that nurtures such traits. On the other hand, Chinese culture is collectivist and values qualities such as obedience and achievement of established standards, so parents raise children in a manner that nurtures those traits. Both types of parenting may produce well-adjusted children, but the definition of well-adjusted can vary across cultures.

"Battle Hymns of the Tiger Mother" offers an entertaining insight into the mindset behind Chinese tiger-parenting in the context of a Western country in a way that is accessible and relatable. It acts as a testament to how "good parenting" can mean different things, depending on cultural values. Amy Chua's intent with this memoir is to contrast Western and Chinese parenting and provide the rationale for why she chose to stick with her Chinese roots when raising her daughters. This memoir has some nuance, as it tells of how Chua's parenting style still resulted in "western" behaviours in her daughter, Lulu. Furthermore, the book acknowledges that both parents and agents of socialization outside the home, such as media, peers, and school, influence the 
behaviour of a child. The target audience of this memoir is unique for its flexibility. Being based on personal experiences makes it relatable and entertaining for the layperson. Academic audiences such as sociologists, family-counsellors, cultural anthropologists, or anyone interested in the rationale of tiger parenting and cultural conflicts between children of immigrants and their parents may benefit from reading this memoir. However, it functions better as a subject of study rather than an information source. Chua cites academic sources to support supplementary claims throughout the memoir, but she does not apply any research methods. The academic sources touch on minor facts such as how to hold a violin or the overrepresentation of Asians in leading music schools (p. 244). The main themes within the book are based on Chua's anecdotes, not the sources.

A final question I have for Chua is about Lulu's origin of rebellion. Indeed, Chua's parenting style would foster obedience to authority and desire to achieve. Lulu is written as the rebellious antithesis to the idealized Chinese daughter, closer to the Western ideal. It is possible she rebelled against her mother under Western influence, as Chua frames it. However, there is an alternative possibility; could it be that Lulu ironically has the sought-after "Chinese" traits of obedience and willingness to fulfill an established standard? The only difference is that Lulu aimed to appease Western culture and achieve within Western standards. I am left to wonder how Chua would address this unique response to tiger-parenting while living in a Western country, which created a distinctly "westernized" child. 